\title{
La responsabilidad social de los medios de comunicación ante el conflicto y la catástrofe
}

\author{
Luis Felipe Solano SANTOS \\ Universidad Complutense de Madrid \\ 1fsolano@yahoo.es
}

Recibido: 6 de enero de 2012

Aceptado: 15 de octubre de 2012

\begin{abstract}
Resumen
¿Qué grado de responsabilidad social le corresponde a los medios de comunicación al afrontar sucesos de extraordinaria dimensión como son las catástrofes, así como conflictos de toda índole? El presente artículo pretende analizar y determinar el quantum de responsabilidad social que incumbe a los mass media en el tratamiento informativo de aquellos hechos y actos cuya envergadura les dota de un carácter de trascendencia universal, y, por supuesto, sus consecuencias. Es decir, la responsabilidad social del periodismo que pasa no sólo por informar objetivamente de lo sucedido, sino también por ofrecer una perspectiva acorde con el conjunto de ideas, valores y creencias que conforma una determinada sociedad en un momento dado.
\end{abstract}

Palabras clave: periodismo; responsabilidad social; conflicto; catástrofe

\section{The Social Responsibility of mass media in facing up social conflicts and natural disasters}

\begin{abstract}
What degree of social responsibility concerns to the media in facing up events of extraordinary dimensions as natural disasters or conflicts of all kinds? This article aims to analyze and determinate the quantum of social responsibility concerned to the mass media in the coverage of those kinds of acts and facts whose scale gives them a character of universal significance, and, of course, its consequences. That is, the social responsibility of journalism that involves not only objective information about what happened, but also offer a matching perspective of the set of ideas, values and beliefs that make up a particular society at a given time.
\end{abstract}

Keywords: journalism, social responsibility, conflict, natural disaster

Referencia normalizada: SOLANO SANTOS, Luis Felipe (2012): "La responsabilidad social de los medios de comunicación ante el conflicto y la catástrofe“. Estudios sobre el mensaje periodístico, vol. 18, núm. 2 (julio-diciembre), págs.: 613-622. Madrid, Servicio de Publicaciones de la Universidad Complutense.

Sumario: 1. Introducción. 2. Fuentes y metodología. 3. Función informativa en cuanto tal. 4. La Responsabilidad Social en el tratamiento informativo de conflictos y catástrofes. 5. Conclusiones. 6. Referencias bibliográficas.

\section{Introducción}

La específica naturaleza del periodismo lo configura como un elemento de progreso del desarrollo social, pero paradójicamente lo configura asimismo como un factor de freno a causa de las circunstancias en las que se desenvuelve a fortiori, que aunque extrañas a su propia esencia, su fuerza es tan poderosa que inevitablemente pueden considerarse como ingredientes esenciales de su propia realidad. Es decir, el periodismo está sujeto a circunstancias exógenas a su propio ser, ineludibles, como son factores políticos, económicos, sociales... De ahí, la extraordinaria importancia que adquiere la responsabilidad social que gravita en el mundo del periodismo, ya que condiciona no sólo la agenda setting de la sociedad, sino también su interpretación de 
los fenómenos sociales, entre los que se encuentran, los conflictos y catástrofes, hechos y actos de una envergadura tal que exige a los medios de comunicación un tratamiento informativo objetivo, riguroso y veraz, es decir, de acuerdo no sólo a lo que la ética determina, sino a una responsabilidad social específica como se reflejará a lo largo de esta investigación.

Informar de hechos noticiables, en primer lugar; y ofrecer una interpretación de los mismos, en segundo lugar; son las principales tareas del ejercicio del periodismo, ya que no sólo se trata de contar lo sucedido, es decir, responder a "qué, por qué, cuándo, cómo, dónde y quién", sino de explicar someramente lo acaecido desde una perspectiva adecuada. Innegablemente, esa explicación o visión está determinada por la situación específica de la sociedad, es decir, por su carácter, valores, ideas y creencias, en definitiva, por su norma de cultura, ese conjunto de convicciones morales conquistado a lo largo de los siglos como respuesta del individuo al desafío del medio (TOYNBEE, 1952); algo que es absolutamente comprensible. No obstante, la interpretación de unos hechos objetivos es susceptible de obedecer no a estos aspectos o factores intrínsecos a un grupo humano que son ineludibles, sino a una serie de intereses de otra índole como pueden ser políticos, económicos, sociales... muy dado, por otra parte, en la cobertura informativa de conflictos y catástrofes, ya que al tratarse de sucesos de una extraordinaria trascendencia, como hemos avanzado, se prestan en numerosísimas ocasiones a convertirse en herramientas tremendamente rentables para satisfacer intereses concretos, que nada tienen que ver con la función periodística.

La responsabilidad social se convierte así en la cortapisa de intereses que no se circunscriben a los propios del ejercicio del periodismo que se basa o debe basarse en un tratamiento informativo que sea exhaustivo, riguroso y fehaciente, es decir, en la asunción de unos criterios profesionales, por un lado; y éticos, por otro, que garantizan o velan por la responsabilidad que incumbe al ejercicio de la función informativa. Es decir, no se trata únicamente de asumir una responsabilidad social genérica, como está sujeto todo medio de comunicación, sino de una responsabilidad social específica que garantice que la función informativa en la cobertura de este tipo de sucesos, de extraordinaria naturaleza, sea la adecuada y necesaria. Para ello, es menester distinguir qué obligaciones se derivan o son inherentes al ejercicio de la profesión periodística, cuyo incumplimiento no supondría, como determina la responsabilidad social, la infracción de la norma de derecho, sino la norma de cultura, lo que redundaría en una devaluación de la imagen del medio de comunicación, del periodista y, por ende, del ejercicio de la profesión periodística, así como afectaría negativamente a la sociedad, ya que se convertiría en la gran perjudicada al no ser informada adecuadamente, lo que supondría una manipulación perversa a causa de los múltiples factores que, en este sentido, acechan al cumplimiento esencial de la responsabilidad social corporativa.

\section{Fuentes y metodología}

Tras determinar en qué consiste la función informativa del periodismo y su relación específica con los conflictos y catástrofes como fenómenos de excepcional envergadura y trascendencia, se procede a establecer su vinculación con la responsabilidad social corporativa, que es desde nuestro punto de vista la esencia de la función 
informativa, esto es, su conexión con el universo de los valores, so pena de considerarla algo inane. Al tratarse de una reflexión teorética, nuestro fin es la determinación conceptual de la función informativa para posteriormente abordar de igual modo el conflicto y la catástrofe; a través de su "cosificación"; la pregunta en consecuencia es cuándo un hecho informativo adquiere la categoría de conflicto o de catástrofe.

La cuestión es de gran importancia porque en un supuesto entra en juego la denominada responsabilidad social, mientras que en otro no hay conexión alguna con la axiología, es decir, el universo de los valores. Un ejemplo aclarará la cuestión: un terremoto, que es un hecho natural, carece per se de conexión con el mundo de los valores, no es bueno ni malo, sin embargo, sí estará conectado con el universo de los valores de acuerdo a cómo sea tratado desde la perspectiva informativa. No obstante, un conflicto sí es, en cuanto tal, algo esencialmente perteneciente al mundo de los valores debido a su conexión con la voluntad de las personas o de los grupos.

Es decir, mientras que, por un lado, el hecho en cuanto fenómeno natural carece de significación, sí la tiene en cuanto hecho cultural; de otro lado, el conflicto es totalmente significativo, tiene un significado, ello quiere decir que forma parte del mundo de lo supraorgánico (SOROKIN, 1947), y su tratamiento sería equivalente al de las ciencias culturales. Verbigracia, una guerra no es un hecho natural, mientras que un terremoto, sí lo es. Por ello se analiza la naturaleza y esencia de cada uno de estos fenómenos, centrándonos fundamentalmente en el conflicto por los motivos expuestos anteriormente, pues su origen es absolutamente social a diferencia de la catástrofe que en la mayoría de las ocasiones es natural.

A pesar de las diferencias en cuanto a su naturaleza, en ambos casos el papel que juega la responsabilidad social es determinante, pues deben abordarse informativamente ambos supuestos desde el rigor, la veracidad, la objetividad y la independencia. Esto es, el periodismo se dota de sentido si está enmarcado en una ética lingüística y de actuación en la elaboración de todos sus mensajes. Sin ética profesional -veracidad, racionalidad e independencia- no existe el periodismo (CASALS, 2006). Advirtamos que en cierto modo el periodismo es independiente de los hechos sobre los que informa; de ahí que la responsabilidad social se pueda predicar exclusivamente de la conexión de la función informativa con una determinada cultura.

En definitiva, nuestro método consiste en fijar exactamente los conceptos que examinamos: la función informativa, la clasificación de los hechos en naturales y culturales, como son las catástrofes y los conflictos, y por último, la responsabilidad social. Una vez fijados, se procede a establecer o determinar el grado de responsabilidad social que incumbe a los medios de comunicación al tratar informativamente este tipo de fenómenos.

\section{La función informativa en cuanto tal}

¿En qué consiste la función informativa? Una primera respuesta muy simple sería que el periodismo agota su función en contar lo que ha ocurrido. Sin embargo, esta respuesta aun siendo verdadera no satisface plenamente nuestros requerimientos porque evidentemente el periodismo no puede limitarse a reflejar especularmente la realidad, sino que debe dar un paso más, entre otras razones, y aunque parezca una paradoja la 
realidad objetiva no existe, ya que está en función de la perspectiva desde la que se contempla. Una analogía nos lo aclarará perfectamente; el aparato de fonación de todos los seres humanos es idéntico y, sin embargo, cuando uno pronuncia una palabra en un idioma distinto a su lengua materna, no reproduce exactamente el mismo sonido al no percibirlo, ya que su percepción está condicionada totalmente por sus circunstancias lingüísticas que son fruto de su cultura.

De otro lado, la subordinación de la función informativa a su público, determina que por razones de índole cultural, dicha función esté sujeta a los requerimientos sociales, que pasan por no sólo informar de lo que sucede, sino también por ofrecer una explicación de lo ocurrido a modo de interpretación adecuada y correcta y desde las perspectivas que así lo exijan para su comprensión y aclaración.

La función informativa, en consecuencia, abarca mucho más de esa primera enunciación que hemos dado. Entiéndasenos bien, ello no quiere decir que esos factores de índole cultural que hemos mencionado lleguen a distorsionar el fenómeno objetivo en cuanto tal, ni siquiera su interpretación más adecuada, sino simplemente que matice la propia esencia objetiva del hecho.

De otro lado, debe tenerse en cuenta asimismo el condicionamiento técnico instrumental, es decir, lo que se considera como un factor cultural de índole esencial (MuMFORD, 1934); este aspecto es determinante y no sólo en el conjunto de instrumentos o aparatos a través de los cuales se realiza la información, sino que comprende otros factores que afectan al ámbito psicológico, como se puso de relieve al distinguir entre medios fríos y medios calientes (McLuHAN, 1967), y que en el ámbito de la televisión determinan respuestas psicológicas completamente diferentes en la audiencia, que tienen una repercusión incluso fisiológica, la conocida hipnosis de la pantalla de televisión.

En definitiva, la función informativa consiste no únicamente en informar sobre lo sucedido, sino en ofrecer una interpretación de la realidad sobre la que se informa. Se trata de cumplimentar los tres requerimientos de la semiótica: sintaxis, semántica y pragmática. Esto es, no sólo el significado de los términos utilizados en el discurso, sino también la norma a que debe obedecer ese lenguaje y, lo que es más importante desde nuestro punto de vista, los efectos presumibles que va a ejercer sobre el receptor o receptores el mensaje, condicionado, como aseveró McLuhan, al afirmar que el medio era el mensaje; en cualquier caso, conviene no exagerar los presumibles efectos del medio utilizado en la transmisión de información, lo que en el fondo ha determinado que la posición del autor canadiense haya experimentado una minusvaloración en nuestros días.

En efecto, si bien es admisible una notable influencia del medio de comunicación utilizado en la función informativa, no es tan decisiva como se presumía en un principio, sin que ello signifique una desestimación de las aportaciones efectuadas en este campo.

\section{La Responsabilidad Social en el tratamiento informativo de conflictos y ca- tástrofes}

Aunque generalmente carece de la menor importancia en la mayoría de los supuestos la procedencia etimológica de los vocablos, un respeto a la tradición académica nos obliga a mencionarla, ello sin tener en cuenta, que por mucho que la evolución haya 
modificado el significado original, éste siempre conserva como una huella indeleble lo que fue en su origen. De ahí, que nos remitamos al significado primigenio de los términos conflicto y catástrofe. En cumplimiento a nuestra determinación procedemos a ello a continuación.

Como sin duda sabrá el lector, el término conflicto procede -cómo no- del latín, conflictus, derivado de confligere, que significa pelear, luchar, combatir... Varias son sus acepciones, pues el término puede designar desde "lo más recio, vivo o empeñado de un combate" hasta "apuro, aprieto, compromiso grave, situación desgraciada y de difícil salida" pasando por "choque, o situación permanente de oposición, desacuerdo o lucha entre personas o cosas".

De otra parte, del griego, katastrophé; significa voltear hacia abajo, ruina, destrucción... Y del latín, catastrophe, significa convulsión, tumulto, desenlace. La catástrofe es un suceso infausto que altera el orden regular de las cosas estrictamente natural.

Conflictos y catástrofes, catástrofes y conflictos, son fenómenos de extraordinaria envergadura y trascendencia y así los vamos a considerar en nuestra investigación.

Ahora bien, adviértase que el aspecto humano se subraya sobre todo en el campo del conflicto, en tanto que la catástrofe se nos ofrece como algo mucho más objetivo e independiente de la acción humana, aunque si es cierto que en contadísimas ocasiones el origen de la catástrofe es consecuencia de un conflicto.

La catástrofe o desastre es un hecho natural o provocado por el ser humano que afecta de forma negativa a la vida, al sustento o a la industria, cuyas consecuencias originan frecuentemente cambios permanentes en las sociedades humanas, en el ecosistema y en el medio ambiente poniendo de manifiesto la vulnerabilidad del equilibrio necesario y fundamental para no sólo progresar, sino y lo que es más importante sobrevivir.

De otra parte, los tipos de conflicto son múltiples y extraordinariamente complicados de clasificar a causa de los diferentes aspectos que rodean cualquier situación humana que requiera unificación y solución de antagonismos, es decir, la constante de fondo que se observa en la historia de la teoría social, el orden y la integración social, que son, en definitiva, la confrontación de dos concepciones distintas de la sociología basadas en una imagen dicotómica de la sociedad (REYEs, 1988).

Los conflictos más frecuentes son de origen familiar, lucha de clases, guerra entre estados, luchas por el poder político, ideologías, intereses profesionales, así como marginación lingüística, racial, religiosa o sexual. Indudablemente es muy variada la cuestión de fondo de un conflicto que casi siempre es social, siempre y cuando transcienda lo individual y proceda de la propia estructura de la sociedad, y así ha de tratarse informativamente, pues supone la lucha por los valores y por el status, el poder y los recursos escasos, en el curso de la cual los oponentes desean neutralizar, dañar o eliminar a sus rivales (COSER, 1956).

Ahora bien, los medios de comunicación, es decir, los periodistas, en el ejercicio de la función informativa deben saber que ciertas formas de conflicto son necesarias para el mantenimiento de la identidad, de la cohesión social y de la delimitación de un grupo social hasta el punto que, en ocasiones, un determinado grupo social no existiría si no viviera en conflicto o en preparación para un conflicto inminente. Es decir, el intento de integración a partir de una situación de desigualdad social provoca un 
conflicto, sin embargo dicho conflicto es precisamente el factor del cambio social. Por ello, el origen de la sociología de este tipo de hechos algunos lo hallan en la opinión de Marx y Engels recogida en el Manifiesto Comunista, donde se expresa que la historia de toda sociedad es la historia de la lucha de clases, lo que indica ya la idea de la existencia de conflicto social y su íntima relación con el cambio de la sociedad.

Evidentemente el periodista debe saber diferenciar qué tipo de conflicto tiene frente a sus ojos, su relevancia y posibles o futuras consecuencias con objeto de abordarlo o tratarlo de forma adecuada, de ahí se derivan una serie de responsabilidades vinculadas a su formación, preparación, habilidad y experiencia, que serán fundamentales a la hora de transmitir al público no sólo lo acaecido, sino la interpretación de lo sucedido. En este sentido, el profesional debe analizar dos aspectos nucleares, la intensidad y la violencia, dos escalas independientes a partir de las cuales puede apreciar o valorar la importancia del conflicto. La intensidad depende del grupo de participación, mientras que la violencia está determinada o se vislumbra a través de las formas de expresión del propio conflicto. Su regulación no conlleva la desaparición de la conflictividad, sino que la canaliza impidiendo que sea destructiva para la sociedad. Entre las formas de canalizar esa conflictividad se encuentra indudablemente el diálogo y la negociación entre las partes beligerantes, la mediación de un tercero, ya sea de forma voluntaria o derivado de normas que así lo determinen y, por supuesto, la implicación de los medios de comunicación que, en este sentido, es esencial, pues se convierten en los altavoces de los principales protagonistas, narradores de todo lo que sucede, es decir, qué, por qué, dónde, cuándo y cómo sucede, y, además, proponen futuribles, soluciones y adelantan posibles consecuencias.

De otra parte, la catástrofe, en cuanto fenómeno natural, ha ejercido y ejerce una influencia, en ocasiones, decisiva sobre el ser humano y, en consecuencia, la sociedad. Esta influencia puede llegar a ser decisiva como lo prueban las grandes catástrofes que ha experimentado nuestro planeta a lo largo de las diversas eras, lo que no es necesario traer a colación; en el presente, bástenos recordar los diversos tsunamis, terremotos... algunos de los cuales han tenido la virtud de alterar radicalmente el curso de la historia universal

¿Qué papel puede jugar la función informativa en el tratamiento de este tipo de fenómeno? En realidad, muy poco, ya que estos fenómenos trascienden en mucho la posibilidad de intervención humana. Por otro lado, aunque no pertenecen al orden natural, puesto que son hijas de la acción humana, por sus consecuencias podemos estimarlos como verdaderas catástrofes. Así, por ejemplo, las explosiones atómicas que desbordan, en muchas ocasiones, las más pesimistas previsiones humanas. Ahora bien, a pesar de la casi imposible intervención humana en dichas consecuencias, si hay un tratamiento preventivo y ahí si juega un papel determinante la acción humana, creando, entre otras cosas, una opinión pública absolutamente contraria a la utilización, en este caso, de la energía atómica o nuclear. Y eso es ya responsabilidad social.

Debe tenerse en cuenta que es precisamente la información sobre conflictos y catástrofes donde brilla o, mejor dicho, destaca la función periodística sin que ello signifique que el periodismo se limite a informar sobre sucesos de esta índole. El hecho de que tenga una repercusión tan importante sobre la función informativa es determinante así 
mismo de la existencia de una especial responsabilidad, y es ahí precisamente donde el papel del informador o periodista determina la existencia propia de una responsabilidad social, dependiente de la específica perspectiva desde la que se aborde el tema.

Una visión simplista del asunto en cuestión, nos diría que la obligación del periodista se agota en informar objetivamente del hecho. Ahora bien, prescindiendo de que una visión totalmente objetiva del tema es materialmente imposible, entre otras cosas, porque el informador proyecta consciente e inconscientemente sobre su información sus actitudes, necesidades, intereses y prejuicios, no es menos cierto que siempre su información adolecerá de ser parcial, entre otras razones, además de las mencionadas, porque él no puede agotar todas las perspectivas desde las que es posible contemplar el suceso. De lo que no hay duda es de que conflictos y catástrofes constituyen el nervio de la actividad periodística, lo que no obstaculiza o impide que haya otro tipo de hechos que vienen a cumplimentar este tipo de informaciones. Sin duda, hay que tener en cuenta que la Responsabilidad Social no elimina otro tipo de responsabilidades, tales como la penal, civil, administrativa, moral... sino que viene a ser una especie de compendio de todas las demás, ya que la infracción de alguna de las restantes responsabilidades siempre afectaría a la responsabilidad social.

La responsabilidad social es un conjunto de obligaciones inherentes a la libre asunción de un estado o condición, aun no tipificadas por el ordenamiento jurídico positivo, pero cuya fuerza vinculante y previa tipificación residen en la íntima convicción social de que su incumplimiento supone la infracción de la norma de cultura (SOLANO FLETA, 1995). Ateniéndonos a esta definición, la responsabilidad social de los medios de comunicación, en lo que a la cobertura de conflictos y catástrofes se refiere, versaría fundamentalmente en informar objetivamente al público de lo sucedido, así como ofrecer una interpretación veraz, rigurosa y, en definitiva, periodística, del origen, causas, evolución, consecuencias y, por supuesto, connotaciones de toda índole, del suceso informativo. Ahora bien, esa interpretación, de innegable carácter cultural, debe responder a un comportamiento o conducta acorde a los requerimientos sociales, sujetos a una norma de cultura determinada. Este tipo de responsabilidad transcurre paralelamente a los derechos y deberes jurídicos que trascienden de la norma jurídica. Pues los medios de comunicación asumen una serie de obligaciones sociales que es imprescindible recordar en todo momento a causa de la sempiterna y extremada importancia que la información y comunicación revisten para el desarrollo social, así como para la evolución de la sociedad y la vida democrática.

Sin embargo, no se trata únicamente de que el profesional asuma o cumpla el código o códigos deontológicos que recopilan los aspectos y fundamentos generales que regulan su comportamiento en el ejercicio de la profesión, sino que la responsabilidad social va mucho más allá, pues se trata de asumir como propias una serie de obligaciones derivadas de la actividad en sí, así como de la enorme trascendencia del que desarrolla dicha actividad al que se le presume una extraordinaria capacidad para influir en el grupo, en este caso, la sociedad. Esto no quiere decir que se ponga en duda la necesidad o eficacia de dichos códigos éticos, sino que no pueden equipararse a lo que realmente significa y aporta la responsabilidad social, que camina en paralelo con objeto de garantizar que los entes colectivos formales, en este caso, los medios de comunicación, desempeñen su actividad desde la misma, lo que asegurará el desenvol- 
vimiento social adecuado y correcto en cuanto al asunto que tratamos, es decir, los conflictos y catástrofes.

Nada más lejos de la realidad está el que la responsabilidad social haya sustituido a la ética como algunos afirman en los últimos tiempos. Cierto es, como hemos subrayado, que caminan en paralelo; pero mientras la ética recoge una serie de pautas y recomendaciones sobre cómo debe actuar y comportarse el profesional en cualquier ámbito, la responsabilidad social atribuye una serie de obligaciones, como ya hemos mencionado, que trascienden la norma jurídica, pero que son ineludibles.

Pero, ¿en qué consiste la responsabilidad social, o más concretamente, por qué los medios de comunicación social están sujetos a una responsabilidad social específica? Una respuesta simplista, sostendría que la sociedad en última instancia se mueve al ritmo que marcan los medios de comunicación social. Hay multitud de teorías que así lo afirman; por ejemplo, la conocida como agenda setting, que más o menos viene a decir, que la gente habla de lo que dicen los medios de comunicación. Pero hay que tener en cuenta, que esto constituiría tan sólo el primer paso, puesto que la gente no sólo habla de ello, sino que además lo hace en el sentido y modo que marcan los medios. De ahí, que se pueda hablar de que los medios de comunicación actuales han secuestrado la opinión pública (HABERMAS, 1962). La sociedad humana ha intentado soslayar este problema a través de la pluralidad de medios. Evidentemente, ésta no es la solución plena, pero más o menos es un factor paliativo. El reconocimiento de este hecho sería ya un factor de justificación que nos permite atribuir que los medios de comunicación social tienen una específica responsabilidad.

Esta responsabilidad tiene diversos matices, sencillamente por el modo en que se habla o se redacta, cómo se trata, incluso el horario de emisión de la información en el supuesto de los medios audiovisuales, así como aquellos factores relacionados con la forma. De ahí, que afirmemos que los medios de comunicación social poseen una específica responsabilidad que no se agota en la simple transmisión del hecho, sino en el modo en el que se presenta la información, casi tan importante como el mismo hecho. Es decir, la forma es casi tan importante como el fondo, y cuando hablamos de fondo nos referimos tanto al hecho en sí como la interpretación que se hace de éste. La forma afecta a la percepción del mensaje por parte del público receptor, determinando su respuesta psicológica.

\section{Conclusiones}

Tras el análisis de los diversos factores que constituyen el hecho informativo de catástrofes y conflictos y la concepción de la responsabilidad social se llega a las siguientes conclusiones:

1. Todo medio de comunicación, como todo elemento social, está sujeto a una responsabilidad social genérica.

2. La especificidad de la función que cumplen los medios de comunicación determina también la existencia de una responsabilidad social genérica que impone esa misma especificidad.

3. Al propio tiempo, la singularidad de los conflictos y catástrofes ejercen también su influencia sobre la responsabilidad social que atañe a los medios de comunicación. 
4. Esa especificidad consiste en la propia función que ejerce el periodismo, cuyo carácter finalista no se agota en la simple función informativa, sino que trasciende al conectar dicho ejercicio con la norma de cultura.

5. En consecuencia, ello implica, la necesidad de un estudio profundo acerca del alcance de esa responsabilidad social, puesto que su naturaleza ya nos es conocida.

En definitiva, la responsabilidad social de los medios de comunicación en el tratamiento de conflictos y catástrofes como hechos y actos de extraordinaria envergadura consiste en asumir una serie de obligaciones ineludibles determinadas por el enorme impacto que éstos tienen sobre la sociedad a todos los niveles. Obligaciones derivadas, no del ordenamiento jurídico positivo, sino de la norma de cultura, es decir, del conjunto de convicciones morales conquistadas a lo largo del tiempo y que hacen relación a los grandes valores (SOlAno SANTOS, 2008).

El medio de comunicación, que nació y se desenvuelve en la sociedad al igual que el resto de empresas u organizaciones, se halla al servicio de ésta y debe colaborar en el mantenimiento del organismo del que recibe la savia nutricia y sin la cual no podría sobrevivir. Esa colaboración consiste en dichas obligaciones enmarcadas en esa específica responsabilidad social a la que nos hemos referido a lo largo del presente trabajo, pues son los medios de comunicación de masas unos formidables instrumentos para transmitir y difundir las informaciones de todo lo que sucede en derredor, así como de las múltiples interpretaciones de las mismas. No obstante, su utilización está sujeta a dicha responsabilidad social, pues los medios de comunicación se han convertido en los poderes fácticos de prácticamente toda sociedad.

La labor periodística frente a conflictos y catástrofes es una labor que exige al profesional lo mejor de sí mismo, pues la enorme importancia de este tipo de acontecimientos así lo requiere. De cómo se trate informativamente el hecho, determinará o marcará el punto de partida de la elaboración cognitiva de dicha información por parte del público al que este tipo de hechos le suscita un interés, no desmedido, sino natural atendiendo al alcance que suponen los conflictos y catástrofes que pueden afectar, cómo no, a nuestra vida diaria directa o indirectamente.

Por consiguiente, es el medio de comunicación, y no viceversa, el que está al servicio de la sociedad, pues detrae de ésta recursos humanos y materiales que podrían aplicarse a otros menesteres. Por tanto, la función informativa en el tratamiento o cobertura de conflictos y catástrofes no sólo debe ceñirse a lo que los códigos deontológicos del periodismo marcan, sino a una responsabilidad social específica que garantizará en todo momento que dicho tratamiento responda a los requerimientos sociales básicos, de acuerdo a la norma de cultura de cada sociedad, y que, en consecuencia, generará una reputación corporativa buena, en el sentido de ser reconocida como valiosa.

Como corolario afirmamos que el conflicto y catástrofe admiten un tratamiento científico-social desde la perspectiva de las ciencias culturales o sociales, lo que los incardina en el ámbito de la significación, en el que tienen explicación. El estudio de estos fenómenos abordados desde la perspectiva de la ciencia cultural tiene la virtud 
de integrarlos en el universo de los valores, esto es, su investigación los integra en el mundo del significado, lo que como es obvio, implica un infinito mundo de perspectivas o enfoques. Es decir, una de las cuales es la conexión con la responsabilidad social, de enorme trascendencia en el ejercicio de la función informativa como queda plasmado en este trabajo.

Somos conscientes de que quedan en el aire numerosas interrogantes sobre el asunto en cuestión al abordarse desde un punto de vista específico. De ahí, que nuestro propósito en esta reflexión sea sobre todo invitar a otros investigadores a que continúen nuestra línea de investigación, en la seguridad de que sus aportaciones infinitamente más autorizadas que las nuestras abrirán nuevos horizontes sobre un tema tan importante y fundamental para la humanidad.

\section{Referencias bibliográficas}

CASALS CARRO, María Jesús (2006): "La enseñanza del periodismo y las nuevas tecnologías de la información y de la comunicación". Estudios sobre el mensaje periodístico, $\mathrm{n}^{\circ}$ 12. Madrid, Servicio de Publicaciones de la Editorial Complutense, pp. 59-70.

COSER, Lewis A. (1956): The Functions of Social Conflict. New York, The Free Press.

HABERMAS, Jürgen (1962): Historia y crítica de la opinión pública. México y Barcelona, Gustavo Gili

MCLUHAN, Marshall (1967): The Medium is the Massage: An Inventory of Effects. New York, Bantam books.

MUMFORD, Lewis (1934; trad. 1997): Technics and Civilization. Técnica y Civilización. Técnica y Civilización. Madrid, Alianza

REYES, Román (1988): Terminología Científico-Social. Barcelona, Anthropos.

SOLANO FLETA, Luis (1995): Fundamentos de las Relaciones Públicas. Madrid, Síntesis.

SOLANO SANTOS, Luis Felipe (2008): Patrocinio y Mecenazgo: Instrumentos de Responsabilidad Social Corporativa. Madrid, Fragua Comunicación.

SOROKIN, Pitirim A. (1947): Personalidad, Cultura y Sociedad. Madrid, Aguilar.

SPENGLER, Oswaldo (1923; trad., 2005): Der Untergang des Abendlandes. La Decadencia de Occidente. Madrid, Taurus/Fundación Ortega y Gasset.

TOYNBEE, Arnold J. (1952): A study of history. Estudio de la Historia. Buenos Aires, Emecé Editores. 